\title{
PROBLEMAS EN LA APLICACIÓN DE LA DESVINCULACIÓN PROCESAL. PRINCIPIO DE DETERMINACIÓN ALTERNATIVA: ALCANCES DEL ARTÍCULO 285-A DEL CÓDIGO DE PROCEDIMIENTOS PENALES
}

\author{
Carlos Escobar Antezano*
}

\begin{abstract}
Resumen
La determinación del hecho punible se limita solo a la descripción fáctica, pues la acusación no tiene un poder de disposición sobre la calificación jurídica de la pretensión, es por ello que la subsunción del hecho en una figura típica realizada por el Ministerio Público en su denuncia o acusación, puede ser modificada en el momento de la emisión del auto de apertura de instrucción, del auto de enjuiciamiento y en una sentencia condenatoria en virtud de la tesis de la desvinculación, siempre que se respeten los requisitos de homogeneidad del bien jurídico tutelado, inmutabilidad de los hechos y de la prueba, preservación del derecho de defensa y la coherencia entre los elementos fácticos y normativos.
\end{abstract}

Palabras Clave: Calificación jurídica - Desvinculación procesal Determinación alternativa.

\begin{abstract}
The determination of a punishable event is limited only to a factual description since an accusation has no power to determine the legal determination of a claim, that is why the inclusion of an event within a typical figure included in the complaint or indictment of the Government Attorney General's Office may be modified at the time of issuing an order to open an investigation, an order of prosecution and a convicting sentence by virtue of the dissociation thesis, provided that requirements of homogeneity of the protected legal right, immutability of the events and evidence, preservation of the right to defense and coherence between factual and regulatory elements are met.
\end{abstract}

Key words: Legal determination - Procedural dissociation - Alternative determination.

\section{Sumario}

1. Conceptos generales. 2. Las garantías procesales y desvinculación procesal. 3. Supuestos en los que opera la desvinculación procesal. 3.1. Cuándo se plantea la tesis de la desvinculación procesal. 3.2. Otro supuesto. 4. ¿En qué etapa se puede aplicar la determinación procesal, con tesis o sin tesis de desvinculación? 5. Solución de casos planteados.

* Juez Superior Titular de la Corte Superior de Lima - Poder Judicial de Perú. 
Carlos Escobar Antezano - Desvinculación procesal y principio de determinación alternativa

A fin de señalar qué problemas trae la desvinculación procesal, es importante empezar por definir qué abarca la desvinculación procesal y en qué casos se aplica.

Para ello es importante indicar que en nuestro país, con fecha 17 de agosto de 2004, se incorporó el artículo 285-A del Código de Procedimientos Penales, donde se plantea la tesis de la determinación alternativa o desvinculación de la calificación jurídica, la misma que ha sido planteada en la Ejecutoria del 3 de julio de 2006, Recurso de Nulidad N²490-2006/La Libertad y en el Acuerdo Plenario Nº 4-2007/CJ-116. La mejor manera de entender cómo los jueces aplican la desvinculación, es referida casuísticamente.

Previamente, se debe establecer conceptos a fin de poder identificar el panorama en el que se plantea la figura de la desvinculación procesal penal.

\section{CONCEPTOS GENERALES}

La figura de la desvinculación procesal penal guarda relación con el objeto del proceso penal, la pretensión punitiva, el objeto de debate y la acusación fiscal. En ese sentido es importante denotar los conceptos y las diferencias, si existieran.

El objeto del proceso penal ${ }^{1}$ está conformado solo por el hecho punible, que es el hecho afirmado por el acusador (el fiscal), primer elemento objetivo de la pretensión penal, que debe mantenerse en el proceso. La calificación jurídica es la subsunción en una figura típica que debe realizar el fiscal en su denuncia o acusación, la que no está sujeta a inmutabilidad, pudiendo variar en el proceso penal. En ese sentido el principio de congruencia penal obedece a que en la acusación y la sentencia se mantenga el mismo hecho, no pudiéndose salir el juzgador de la acusación punitiva, pues ello supone salirse de los términos del objeto del proceso.

En atención a ello, se entiende que el sujeto que determina el objeto del proceso (el hecho punible) es el fiscal, mientras que la calificación jurídica es exclusiva del juez.

Con relación a la pretensión punitiva, está conformada por la solicitud de condena e imposición de una pena, objeto que no es titular el acusador, pues no tiene un derecho subjetivo, sino que la delimitación viene impuesta por la ley, al tener que perseguir un hecho considerado delictivo, que expone en su acusación escrita, que debe ser de conocimiento del procesado a fin que no se genere indefensión. 
Se entiende por objeto de debate lo que argumenta el acusado, explica en uso del derecho de defensa, el derecho a ser informado de la acusación y de los cargos, tanto de los hechos y la calificación jurídica, y la pena que solicita el fiscal. Por ello, la denuncia o acusación realizada por el fiscal debe contener dichos elementos.

Del estudio de la doctrina y de los instrumentos señalados, se ha fijado que el objeto del proceso (hecho punible) tiene como requisitos constitutivos:

1. Inmutable: se va limitando progresivamente, se va definiendo el hecho mediante el desarrollo de la instrucción.

2. Indivisible: el hecho debe conformar el objeto del proceso penal con todas las circunstancias y los actos que la componen.

3. Indisponibilidad: las partes no quedan a disposición de los sujetos del proceso, sino que se mantiene incólume.

\section{GARANTÍAS PROCESALES Y DESVINCULACIÓN PROCESAL}

Es importante resaltar que la problemática de la aplicación de la desvinculación penal se debe a que afecta el principio acusatorio, el principio de imparcialidad, el derecho de defensa y el principio de contradicción.

El hecho punible (objeto del proceso penal y concreta conducta o hecho histórico atribuido al imputado) es fijado por la fiscalía ${ }^{2}$ en virtud de la titularidad de la acción penal que posee; sin embargo, la determinación del hecho punible, se limita solo a la descripción fáctica (proposición fáctica), pues la acusación no tiene un poder de disposición sobre la calificación jurídica de la pretensión (hecho punible), es vinculante la imputación jurídica del hecho ${ }^{3}$.

En atención al principio acusatorio, el titular es el fiscal, quien determina en acusar y postula el hecho punible mediante su escrito de acusación (artículo $225^{\circ}$ del Código de Procedimientos Penales), el que implica que se determine la calificación jurídica (fundamentación jurídica) y solicita una pena. Observamos que la calificación jurídica realizada por el Ministerio Público puede ser modificada en el momento de la emisión del auto de apertura de instrucción, del auto de enjuiciamiento y en una sentencia condenatoria en virtud de la tesis de la desvinculación (siendo aplicable ello cuando no se modifique el hecho y cuando haya homogeneidad del bien jurídico).

La no vinculación de la calificación jurídica se fundamenta en el principio del iura novit curia, pues se viene admitiendo que la calificación jurídica que hagan 
las partes respecto de los hechos no pueden vincular al juez, el cual tiene, por un lado, el deber de conocer el derecho y, por otro, el de calificar jurídicamente los hechos sin estar vinculados por las calificaciones de las partes ${ }^{4}$.

Se ha pronunciado el Tribunal Constitucional, en la sentencia Expediente $\mathrm{N}^{\circ}$ 00031-2009-PHC/TC, Ayacucho, caso Jorge Luis Arellano Alania, realizando un análisis de los roles de los sujetos del proceso, siendo el rol del Ministerio Público sostener su tesis incriminatoria hasta conseguir la concretización del ius puniendi, a no ser que antes del término del mismo solicite el sobreseimiento o retire su acusación, siendo el contenido de la formalización de denuncia que efectúa el representante del Ministerio Público posee una doble estructura, una fáctica y otra jurídica. La fáctica estaría representada por el conjunto de hechos acontecidos, los mismos que lesionan o ponen en peligro bienes jurídico-penalmente relevantes. La otra estaría representada por la calificación jurídica que sobre los hechos efectúa el encargado de ejercitar la acción penal, consecuentemente el juez tiene constitucionalmente habilitada la facultad de variar la formulación jurídica hecha por el representante del Ministerio Público en su formalización de denuncia; más aún cuando al juez penal le corresponde efectuar el "juicio de tipicidad, que en rigor es la valoración que se hace con miras a determinar si la conducta objeto de examen coincide o no con la descripción típica contenida en la ley".

La desvinculación de la calificación jurídica permite a la sala o al juzgador penal apartarse de la calificación jurídica dada por el representante del Ministerio Público, mientras no se altere el hecho (punible) propuesto por este. Es importante determinar quien es el titular de la delimitación del hecho punible y de la calificación jurídica; el artículo 285-A recién se incorporó en el año 2004, ello no ha impedido desarrollar con anterioridad el ámbito dogmático y jurisprudencial.

Asimismo, nuestro ordenamiento dispone que se declare nulo cuando se condena por hecho que no ha sido materia de la acusación fiscal, es decir, no ha sido objeto de proceso, de conformidad con el artículo $298^{\circ}$. Por consiguiente, de la identificación de la fundamentación fáctica solo comprende el hecho natural. Este no viene dado por la calificación jurídica ni por la entidad o cuantía de la pena pedida por un acaecer histórico, individualizado en su unidad natural y no en la jurídico penal, de que se pretende sacar una consecuencia jurídica penal, cualquiera que ella sea ${ }^{5}$. 


\section{SUPUESTOS EN LOS QUE OPERA LA DESVINCULACIÓN PROCESAL}

Para los supuestos en el que se aplica la desvinculación procesal es importante indicar los requisitos de la determinación alternativa o desvinculación que son: a) homogeneidad del bien jurídico ${ }^{6}$ tutelado; b) inmutabilidad de los hechos y de las pruebas; c) la preservación del derecho de defensa, y; d) la coherencia entre los elementos fácticos y normativos para realizar la correcta adecuación al tipo penal ${ }^{7}$.

Conforme regula el artículo 285-A del Código de Procedimientos Penales y el Acuerdo Plenario 4 - 2007/CJ-116, los supuestos son:

\subsection{Cuándo se plantea la tesis de la desvinculación procesal}

a) El tribunal advierte que concurre una circunstancia modificativa de la responsabilidad penal no incluida en la acusación que aumenta la punibilidad o que justifique la imposición de una medida de seguridad, en cuanto a la justificación jurídica del hecho objeto de imputación.

La tesis no es una circunstancia de atenuación; sin embargo, los bienes jurídicos deben ser homogéneos (entendidos como el mismo interés, modalidades distintas pero cercanas dentro de la tipicidad penal) y como concurre las denominadas circunstancias modificativas ${ }^{8}$ son como se sabe, elementos fácticos accidentales del delito, contingentes o no esenciales, que no pueden servir de fundamento al injusto o la culpabilidad como son por ejemplo de un delito de homicidio a un delito de asesinato se debe poner en conocimiento la circunstancia agravante.

Se puede plantear la tesis en aspectos de autoría y participación cuando tiene una condición de cómplice se adecua y se coloca en la situación de autor, al ser una circunstancia agravante, debe realizarse la tesis de la desvinculación conforme lo señala el artículo 285-A del Código de Procedimientos Penales.

b) Se aplica la desvinculación cuando existe una errónea tipificación en los requisitos establecidos, como pertenecer al mismo bien jurídico, inmutabilidad de hecho y de las pruebas del proceso. Esta desvinculación se puede dar en el juicio de tipificación en el auto de enjuiciamiento, en el auto de apertura de instrucción o en el desarrollo del juicio oral hasta antes de la acusación fiscal final o la requisitoria oral, siempre que el hecho fáctico ha sido mal tipificado, por ejemplo: un hecho " $x$ " ha sido encuadrado erróneamente en el delito de 
peculado cuando es un delito de malversación de fondos, el juez debe plantear la tesis de la desvinculación, pues existe inmutabilidad de los hechos y las pruebas, se garantiza la homogeneidad de los bienes.

Otro caso, es cuando en el proceso se establece que existe una calificación manifiesta errónea como ejemplo de una usurpación simple a una usurpación agravada o al revés.

Es decir, se puede plantear la tesis de la desvinculación cuando se dé una nueva tipificación o se incorporen circunstancias agravantes que tienen bienes jurídicos homólogos, dándose al acusado oportunidad de poder defenderse y presentar nuevas pruebas, tanto en el proceso sumario como en el proceso ordinario, siempre antes de la acusación fiscal.

Por ello, el procedimiento de la desvinculación penal (la determinación alternativa) contenida en el Código de Procedimientos Penales señala que cuando se realiza la tesis de la desvinculación, la Sala, de oficio, indica al acusado esta posibilidad y concede la oportunidad para defenderse (principio del contradictorio y conocimiento de los cargos), y siempre que la nueva calificación no exceda su competencia. Por ejemplo, de un delito de violación sexual a un delito de actos contra el pudor. En ese sentido tenemos que se otorga un plazo hasta de ocho días, en el juicio oral, a fin de organizar su defensa por la nueva calificación jurídica o cuando concurra una "circunstancia modificativa" de la responsabilidad, pudiendo presentarse nuevas pruebas en relación a esos cargos.

En el caso de un delito doloso a un delito culposo no se puede realizar la desvinculación al existir un hecho punible diferente, pues el dolo o culpa forman parte del título de imputación. En ese sentido, si aparece en un proceso un hecho nuevo que traduce culpa, entonces se debe dar una acusación complementaria o denuncia ampliatoria (proceso ordinario o sumario respectivamente), pues se está incluyendo un hecho nuevo que varía la calificación jurídica por más que se esté dentro de un mismo bien jurídico. Y que la pronunciación del juez a fin de adecuar producirá una afectación del principio de imparcialidad, pues asumiría el papel de acusador, calidad jurídica que solo recae en la autoridad fiscal. En ese lineamiento, si en un proceso el juez advierte un nuevo hecho que no es materia del proceso, solo el fiscal puede incorporar dicho hecho. Si lo advierte el juez debe inhibirse.

En un delito de apropiación ilícita se advierte que el sujeto activo es un funcionario público, el juez no podría desvincularse, pues el hecho punible 
ha cambiado salvo que el fiscal pida ampliación de la denuncia o pida que se adecue al incorporar el nuevo hecho, así tampoco si fuera al revés pues la calidad jurídica implica un deber positivo y negativo diferentes que forman parte de la imputación, al ser diferentes bienes jurídicos; situación diferente es que exista una errónea tipificación, supeditado a que esté dentro del mismo bien jurídico.

\subsection{Otro supuesto, (que ha sido desarrollado por el Acuerdo Plenario) indica que se puede dar la determinación procesal sin necesidad de plantear la tesis de la desvinculación procesal cuando:}

a) El acusado en la realización de su defensa ha reconocido una diversa calificación jurídica de los hechos acusados; por ejemplo, reconoce haberse apoderado del bien, pero no que se realizó en la noche, o señala que ha actuado solo. Debiendo ser evidente que incorporó esa circunstancia en su planteamiento de estrategia defensiva [alegatos finales de su abogado y defensa material]. Pues, no se afecta el principio acusatorio ni el derecho de defensa ni el principio de contradicción, por lo que en aplicación del principio del iura novit curia se puede aplican la desvinculación.

b) En un caso de error manifiesto en la tipificación, fácilmente constatable por la defensa, al no producirse un supuesto de indefensión, en tanto que todos y cada uno de los sujetos puede predecir, no es necesario la desvinculación, por ejemplo que se procesa a una persona por el delito de hurto agravado en vehículo motorizado, sin embargo los actos de investigación determinan que es un hurto simple.

c) No se plantea la tesis de la desvinculación cuando se introduce una circunstancia de atenuación o varía el grado del delito o el título de participación. Por ejemplo, no era un asesinato sino un homicidio, de un hurto agravado a hurto simple, de la calidad de autor a cómplice, el hecho era considerado consumado pero se sentencia declarando en grado de tentativa, es decir, la desvinculación va de más a menos o viceversa.

En el juicio oral, si observamos que la descripción fáctica (el hecho punible) del Ministerio Público no ha sido corroborado con medios de prueba, la acción típica se delimita en virtud del mismo bien jurídico protegido y existe coherencia en el juicio de subsunción típica9 ${ }^{9}$, siendo por tanto viable a la adecuación del tipo penal imputado. 


\section{4. ¿EN QUÉ ETAPA SE PUEDE APLICAR LA DETERMINACIÓN PROCESAL, CON TESIS O SIN TESIS DE DESVINCULACIÓN?}

El Código no señala la etapa exacta, en el caso de producirse, se plantea que la tesis de desvinculación debe ser invocada hasta antes de emitir sentencia en el juicio ordinario; es decir, terminada la etapa probatoria hasta antes que se emita la acusación final, o alegatos finales. Cuando en el debate se advierte la circunstancia agravante o la tipificación que no corresponde al hecho punible. Nuestro sistema jurídico comprende los procesos sumarios (la mayoría de los delitos), proceso que si bien no tiene una etapa de juicio oral, se puede plantear la tesis de la desvinculación hasta antes que se emita el dictamen final, puede también el juez plantearla en los supuestos de circunstancia agravante o si la tipificación no corresponde al hecho punible.

En ese orden de ideas, el juez penal, en los procesos sumarios, puede plantear la determinación penal, sin desvincularse en los supuestos que realizando la variación del grado de participación, la variación de circunstancias atenuantes, o cuando varía el grado del delito o cuando la defensa reconoce una calificación jurídica. En igual sentido, si un órgano en segunda instancia tiene una sentencia condenatoria puede desvincularse en los supuestos citados cuando no es necesario el planteamiento de la tesis, situación distinta, es cuando se impugna una sentencia que tiene una circunstancia modificativa de la responsabilidad penal no incluida en la acusación que aumente la punibilidad o que justifique la imposición de una medida de seguridad o cuando exista un error manifiestó en la tipificación se debe realizar la desvinculación penal y declarar nula la sentencia de primera instancia. Al ser la desvinculación procesal facultad de todos los juzgadores en todos los niveles, pudiendo aplicarlo en cualquier proceso siempre que se garantice los requisitos señalados.

\section{SOLUCIÓN DE CASOS PLANTEADOS}

En un caso, se imputa fácticamente a los procesados haber presentado a una licitación pública documentos falsificados, se les imputa la falsificación de los documentos en un inicio; sin embargo, en el proceso se prueba que se ha usado el documento. Se presenta las siguientes alternativas: si el defensor del procesado reconoce haber realizado la conducta de usar en sus alegatos, en base a las alegaciones del procesado, testigo y afectados, se mantiene la inmutabilidad del hecho, pues se puede realizar la adecuada tipificación sin plantear la tesis de desvinculación procesal penal, sin embargo, si la defensa no reconoce el uso del documento y el hecho punible es haber falsificado, entonces el usar 
constituye un nuevo hecho que el a quo no puede desvincularse, si lo advierte el juez revisor debe inhibirse, a lo sumo podría declararla nula, debiendo inhibirse. Esto solo es en los casos que aún se mantenga dentro del mismo bien jurídico, circunstancia distinta es si el bien jurídico es diferente, no se podría realizar la desvinculación debiendo sufrir el Estado las consecuencias de dicha situación, pues se afectaría el derecho a defenderse del procesado.

Citando el caso del delito de estelionato que ha sido erróneamente tipificado, que debió ser encuadrado en el tipo penal de estafa (delito sometido a pena mayor); el juez a quem debe declarar nula y adecuar el delito.

En el caso de la calificación jurídica a la que ha sido encuadrado el hecho punible ha sido declarada prescrita se debe evaluar que los plazos de prescripción surgen a partir de la calificación jurídica asignada al delito, por lo que si esta es errónea no se puede contabilizar correctamente la prescripción de la acción penal, la misma que el fiscal inicia en base al hecho punible al ser postulada por el órgano perseguidor del delito.

Por ello, es importante que los juzgadores en todos los niveles al seguir un proceso ya sea en su actuación desde el auto de apertura de instrucción hasta ante de emitir sentencia planteen la tesis de la desvinculación realizando un juicio de subsunción penal: entendida como la operación mental (proceso de adecuación valorativa conducta - tipo) llevada a cabo por el interprete (juez) mediante la cual se constata o verifica la concordancia entre el comportamiento estudiado y la descripción típica consignada en el texto legal. La norma típica debe ser vigente, valida formal y material. Queda claro entonces que lo que puede ser objeto de variación es la calificación jurídica de los hechos, pues como se ha expresado líneas arriba, es el juez el llamado a ser el "responsable" del juicio de tipicidad. Teniendo como fuente el contenido de la formalización de denuncia es lo único que puede modificar, mas no el sustento fáctico pues es de exclusividad del representante del Ministerio Público ${ }^{10}$.

También en la sentencia se puede plantear si existe un concurso de delitos (real, ideal o aparente), debe realizar primero el juicio de tipicidad penal, exponer en la parte considerativa los fundamentos y solo en el fallo colocar el tipo penal adecuado que postula el fiscal, para después emitir un fallo sobre la responsabilidad.

En igual sentido, el juez cuando resuelve una excepción de naturaleza de acción planteada debe realizar el juicio de tipicidad por lo que si advierte que el hecho ha sido erróneamente tipificado no corresponde a la calificación 
Carlos Escobar Antezano - Desvinculación procesal y principio de determinación alternativa

jurídica sino a otro, debe desvincularse o advertir al fiscal (cuando existe bienes jurídicos diferentes) que se dé la adecuación correcta debiendo en este último caso apartarse de la causa porque constituye un nuevo hecho.

El juez "decide el derecho", no es un simple tramitador de la denuncia formulada por el representante del Ministerio Público, lo cual no condice con la naturaleza del Estado constitucional de derecho, tarea que debe ser realizada dentro del marco de los requisitos y supuestos expuestos para la institución de la desvinculación procesal penal.

\footnotetext{
Montero Aroca, Juan. Derecho procesal penal. Valencia: Tirant lo Blanch, pp. 322-342.

Acuerdo Plenario N ${ }^{\circ} 4-2007 / C J-116$.

San Martín Castro, César. Derecho procesal penal. Lima: Grijley, 2003, p. 419.

Montero Aroca, Juan. Principios del proceso penal. Valencia: Tirant lo Blanch, 1997, p. 121.

5 Gómez Orbabeja, Emilio. Comentarios a la Ley de Enjuiciamiento Criminal. T. I. Barcelona: Bosch, 1947, p. 52.

6 Esta es relevante por lo que no podría darse la desvinculación en bienes jurídicos de diferentes tipos penales. Autores como Yaipén Zapata, Víctor. Desvinculación procesal. Alcances del artículo $285^{\circ}$ del Código Procesal Penal en jurisprudencia vinculante; Castillo Alva, 2008, p. 1109 y siguientes, postulan que puede también aplicarse a bienes jurídicos diferentes, situación que no es compartida por el ponente de este artículo.

7 Sánchez Velarde, Pablo. Manual de derecho procesal penal. Lima: Idemsa, 2004, p. 418. Acuerdo Plenario N 4-2007/CJ-116. San Martín Castro, César. Ob. Cit., p. 419.

8 Acuerdo Plenario $N^{\circ} 4-2007 / C J-116$.

9 Acuerdo Plenario N. ${ }^{\circ} 1-2008 / \mathrm{CJ}-116$.

10 Expediente $\mathrm{N}^{\circ}$ 00031-2009-PHC/TC, Ayacucho, caso de Jorge Luis Arellano Alania.
} 